\title{
DEVIR-LOUCURA NO RÁDIO: \\ UMA EXPERIÊNCIA EM SAÚDE MENTAL
}

\author{
Fernanda Fontana Streppel \\ Analice de Lima Palombini $\star \star$
}

\begin{abstract}
Resumo
Este texto pretende apresentar esboços de uma pesquisa que se realiza a partir de uma experiência de produção de rádio em saúde mental - Coletivo de Rádio Potência Mental -, discutindo alguns aspectos referentes às especificidades do seu processo de produção discursiva, assim como o estatuto da loucura no seu fazer. O programa é produzido por quem chamamos de "diagnosticados", pessoas com diagnóstico psiquiátrico, e estudantes e profissionais de Psicologia e Comunicação Social, diagnosticados ou não. As discussões são disparadas pelo que se configura como uma cartografia do Coletivo de Rádio, inspirada no pensamento de Deleuze e Guattari, através da qual se assiste ao transcorrer de uma pesquisa que se utiliza da mesma experiência de coletivo que se faz sujeito, objeto e método da investigação para cunhar uma noção de devir-loucura que transpõe a linha da loucura da interioridade dos diagnosticados para carregar todo o processo de produção radiofônica em direção ao Fora.
\end{abstract}

Palavras-chave: rádio; saúde mental; loucura; coletivo; devir.

\section{Madness-becoming on the Radio:}

\section{AN EXPERIENCE IN MENTAL HEALTH}

\begin{abstract}
This paper aims to present drafts of a research that is conducted from a radio production experience in mental health - Radio Collective Mental Potency - and discusses some aspects related to the specificities of its process of discursive production, as well the crazyness status in its practice. The show is produced by those we call "diagnosed" with psychiatric disorders, and students and professionals in Psychology and Social Communication, diagnosed or not. The discussions are triggered by what is configured as a cartography of the Radio

\footnotetext{
^ Mestranda bolsista CAPES/PROF do PPGPSI - Programa de Pós-Graduação em Psicologia Social e Institucional da Universidade Federal do Rio Grande do Sul. Endereço: Rua Ramiro Barcelos, 2600 - Sala 13 - Térreo- Porto Alegre - RS - Brasil. CEP: 90035-003

E-mail: ffstreppel@yahoo.com.br Federal do Rio Grande do Sul. Endereço: Universidade Federal do Rio Grande do Sul. Avenida Ramiro Barcelos 2600 sala 105, São Manoel - Porto Alegre, RS - Brasil. CEP: 90035-003.

E-mail: analicepalombini@uol.com.br.
}

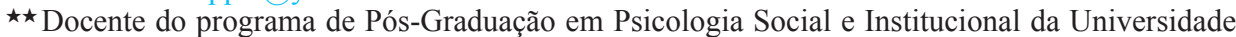


Collective, inspired by the thought of Deleuze and Guattari, through which one watches the course of a research which uses the same collective experience that is subject, object and research method to coin a notion of madness-becoming transposing the line of crazyness from the interior of diagnosed people to embrace the whole process of radio production toward the Outside.

Keywords: radio; mental health; madness, collective; becoming.

\section{INTRODUÇÃ̃o}

Este texto pretende apresentar esboços de uma pesquisa que se realiza a partir de uma experiência de produção de rádio em saúde mental - Coletivo de Rádio Potência Mental -, discutindo alguns aspectos referentes às especificidades do seu processo de produção discursiva, assim como pensar o estatuto da loucura no seu fazer.

Trata-se de uma experiência que acontece em Porto Alegre/RS, com a produção de um programa radiofônico por usuários de serviços de Saúde Mental, aos quais nos referiremos como "diagnosticados", isto é, pessoas com a marca de um diagnóstico e de uma inserção no universo psiquiátrico, além de estudantes e profissionais de Psicologia e Comunicação Social, diagnosticados ou não. O programa tem trinta minutos de duração e é veiculado quinzenalmente pela Rádio Comunitária da Lomba do Pinheiro (FM 87,9).

O trabalho investe na comunicação da diferença, como trazida por Caiafa (2004), que, fugindo da hegemonia dos códigos de reconhecimento, aposta na produção de diferenças para a realização da comunicação efetiva, através da idéia de outrem como uma instância de diferenciação. Outrem expressa um mundo virtual (real, mas não atualizado) que se remete ao Fora ${ }^{1}$ e faz a comunicação gaguejar, a partir dos pressupostos deleuze-guattarianos. Com Guattari, pensamos a possibilidade que o rádio tem, enquanto meio de comunicação, de agenciar a experimentação da democracia e da expressão livre (GUATTARI, 2005; GUATTARI; ROLNIK, 1999).

Quanto ao estatuto dos diagnosticados, algo do texto original desta pesqui$\mathrm{sa}^{2}$ a eles se referia como "a princípio e em teoria pessoas em sofrimento psíquico, ou, em outras palavras, psicóticos ou loucos" (STREPPEL, PALOMBINI, 2011). Diante da diferença entre os termos "sofrimento psíquico", "psicose" e "loucura", num segundo momento, o último se fez mais condizente com a presente proposta, uma vez que remete a um modo de vida e não a um enquadramento psi. Porém, no transcurso da experiência que aqui se relata brevemente, mesmo a loucura como modo de vida foi cada vez mais se relativizando. Para marcar a diferença entre o sentido que aqui queremos reverberar para a mesma e o estatuto dos "diagnosticados", optamos então por tomar este termo de empréstimo da Associação Cultural Rádio Nikosia, apresentada adiante, marcando a questão do diagnóstico como 
independente em relação à loucura que aqui propomos. Por isso, o que interessa ao Coletivo e à pesquisa é justamente a experiência de produção radiofônica pelo "encontro louco de pessoas" e, especialmente, "discursos diferentes".

É dessa forma que a forjada separação usuários diagnosticados x profissionais não diagnosticados é denunciada, no mínimo, por dois participantes: um diagnosticado jornalista e um diagnosticado estudante de Psicologia (ou um jornalista diagnosticado e um estudante de Psicologia diagnosticado). Na medida em que avançamos neste sentido, a loucura revela-se fora das pessoas e alocada cada vez mais no encontro.

\section{RÁdios COLIFATAS E A MARCA do POTÊNCIA MENTAL}

Uma das primeiras rádios chamadas colifatas de que se tem notícia é a Rádio Tam Tam, que remonta a 1989, quando decretada a intervenção da administração municipal de Santos/SP sobre a Casa de Saúde Anchieta, para desmontar o hospício. Através do arte-educador Renato Di Renzo, iniciou-se um trabalho terapêutico com proposta artística e cultural, sendo uma das iniciativas justamente a Rádio, "feita pelos próprios pacientes que se autodenominavam 'loucutores"'. Começou como experiência dentro do Anchieta, passou a ser veiculada pela Rádio Universal AM em 1990 e durou sete anos (ASSOCIAÇÃO PROJETO TAM TAM, 2009).

Outra experiência importante é a Rádio La Colifata (da gíria que significa "maluco adorável"), que emite regular e semanalmente desde 1991, de dentro do Hospital Psiquiátrico José Tiburcio Borda, de Buenos Aires, capital da Argentina. A iniciativa surgiu em 1986, através do grupo Cooperanza, que pretendia apagar a separação entre o dentro e o fora do manicômio. Começou com uma coluna na Rádio FM Comunitária de San Andrés, província de Buenos Aires, para depois se independizar e tornar-se uma emissora autônoma. Até hoje, reunidos no pátio do hospital, os internos, exinternos e pessoas da comunidade emitem ao vivo nos sábados, e suas gravações são veiculadas em forma de programas curtos em muitas outras emissoras nacionais e internacionais. $\mathrm{O}$ projeto tem ambições políticas, ético-terapêuticas e estéticas (CHAO, 2009; OLIVERA, 2003, 1999).

O trabalho da Rádio La Colifata impulsionou a criação da Rádio Nikosia, que acontece em Barcelona/Espanha, no momento em que a cidade vive o que se chama de pós-Reforma Psiquiátrica: conta com uma rede de serviços substitutivos ao manicômio, bem estabelecida e bastante funcional, permitindo relativa autonomia às pessoas acometidas de sofrimento psíquico; mas não garante por si só o fim da discriminação porque o modelo biomédico vigente se encarrega de reduzir os sujeitos à sua doença. Assim, incitado pelo contato com La Colifata, em 2002 Martín Correa-Urquiza inicia um trabalho similar em Barcelona, abdicando do enfoque clínico para que se proporcionassem outros papéis sociais aos chamados diagnosticados, longe das amarras do modelo biomédico. (CORREA-URQUIZA, 2009) 
Emitindo seus programas semanalmente ao vivo pela Rádio Contrabanda $\mathrm{FM},{ }^{3}$ mantida por coletivos defensores de discursos marginais frente às grandes mídias e localizada em frente à Plaza Real, em pleno centro de Barcelona (PALOMBINI; CABRAL; BELLOC, 2008), a Rádio Nikosia deseja "hablar de la locura desde la voz que la sufre, para soltarse a esa posibilidad de hacer un tipo de política de subsuelo, cierta militancia desde el margen que [...] increpa a la locura, la cuestiona, se refugia en ella, la expulsa, la redefine" (RADIO NIKOSIA, 2010). Os nikosianos - diagnosticados redatores do programa de rádio - se autogestionam através da "Asociación Socio-Cultural Radio Nikosia".

Além dessas, outras experiências de rádio em saúde mental, geralmente referidas a serviços de saúde e a ambições políticas e terapêuticas, são a Rádio Maluco Beleza, que acontece desde 2002 no Serviço de Saúde Dr. Cândido Ferreira, em Campinas/SP/Brasil (ROLDÃO; MOREIRA, 2007; SERVIÇO DE SAÚDE DR. CÂNDIDO FERREIRA, 2010); a rádio De Perto Ninguém é Normal, produzido desde 1999 por usuários do CAPS II Prado Veppo, da Prefeitura Municipal de Santa Maria/RS/Brasil, e veiculado quinzenalmente ao vivo na Rádio Universidade da Universidade Federal de Santa Maria (MELO; MAGNAGO, 2008; PORTAL RÁDIO UNIVERSIDADE, 2010); o programa Papo Cabeça, produzido também desde 1999 pelo CAPS de Santa Cruz do Sul/RS/Brasil em parceria com o Departamento de Comunicação Social da Universidade de Santa Cruz do Sul, gravado e veiculado quinzenalmente na Rádio Gazeta, emissora comercial local (MELLO, 2001); o programa Cuca Legal, produzido pelos usuários do CAPS I Nossa Casa de São Lourenço do Sul/ RS/Brasil, desde 2005, veiculado semanalmente na Rádio Comunitária Vida FM (HAMMES, 2008, p. 125); dentre outras como: Rádio Zondita (Hospital Psiquiátrico El Zonda - San Juan, Argentina); Rádio Vilardevoz (Hospital Psiquiátrico Vilardebo - Montevideo, Uruguai); Rádio Durchegknallt (Centro de Saúde de Nuremberg, Alemanha); Rádio "El encendedor" (Hospital Psiquiátrico Melchor Romero - Buenos Aires, Argentina), Rádio "La Vitrina" (Centro de Saúde Mental de Collado Villalba, España); Rádio "Estación Paraíso" (Hospital Psiquiátrico El Peral - Santiago do Chile); etc. (OLIVERA, 1999, 2003)

Desse universo emerge o Coletivo de Rádio Potência Mental, desde 2006, através de um grupo de residentes em Saúde Mental Coletiva, ${ }^{4}$ inspirado em um seminário da Residência, ministrado por Martín Correa-Urquiza, da Rádio Nikosia. As residentes encontraram suporte na Rádio Comunitária da Lomba do Pinheiro, onde se começou a emitir quinzenalmente o programa Potência Mental, dentro da janela Comunidade em Ação, reunindo usuários de diversos serviços de saúde de Porto Alegre e Viamão nessa produção - configurada como atenção psicossocial num contexto de formação e trabalho em saúde e conquista de espaços para a loucura no cotidiano da cidade.

Sobre este que era um programa de variedades, com foco no tema da saúde mental, as residentes contam:

Pensamos que o programa vem se constituindo um intenso canteiro de experimentações. Pois se já prevíamos a 
experimentação de novos lugares pelos usuários, que agora já podemos chamar nossos parceiros na produção da rádio, talvez não estivesse tão claro, no princípio, o desafio que seria para nós também ocuparmos outro lugar. [...] Afinal, estamos fazendo este programa para os usuários, em benefício deles? Ou é com eles que fizemos? E, mais, tomamos ali a comunicação como um meio pelo qual acontece a atenção psicossocial? E assim seria uma intervenção da saúde? Ou é possível pensar na rádio, não como meio, mas como a produção em si? (TIBULO et al., 2006, p. 3)

Desde lá, as tarefas eram divididas por todos os loucutores, ${ }^{5}$ circulando entre residentes e usuários dos serviços de saúde, e, além disso, descentralizando as decisões. O Coletivo já se debatia também com o que se estabeleceria como traço característico ao longo de sua trajetória: os conflitos entre estruturação e espontaneidade na produção radiofônica.

Em 2008, reforça-se o suporte institucional do Instituto de Psicologia da UFRGS, na forma de ação de extensão, o que possibilitou a integração de novos participantes. Um importante marco de 2009 é a premiação do Coletivo no Concurso Público Cultural Loucos pela Diversidade, do Ministério da Cultura e Escola Nacional de Saúde Pública/Fundação Oswaldo Cruz, e, ainda, a contemplação pelo edital Proext/2009, do Ministério da Educação, articulado a outras duas ações que abordam o uso de tecnologias de informação e comunicação na saúde mental. ${ }^{6}$

A partir de 2008, com o engajamento no grupo de um estudante de Psicologia militante, uma doutora em Comunicação Social e um jornalista, diagnosticados ou não, a dimensão saúde perdeu um pouco da sua centralidade para ceder espaço à comunicação. Os temas parecem ter-se desviado do foco, saltando em várias direções. Além de Saúde Mental e afins, como respeito, preconceito, diferença, os programas também tratam de terrorismo, alimentação, teatro, Natal, relacionamentos, "eu e o fantasma", aborto, flores, gravidez, entre outros assuntos que se configuram temática principal ou atravessam os programas.

Essa talvez seja uma das balizas do Coletivo na atualidade (entendendose atual como tudo aquilo que sempre se está deixando de ser): a renúncia tanto à dimensão terapêutica quanto anti-estigmatizante enquanto "núcleos" das produções, marcando a diferença diante de si mesma e de outras rádios em saúde mental. Porém, embora renuncie à centralidade dessas ambições, não se furta às mesmas. Para alguns, a rádio é terapêutica, para outros, desafia a vergonha de falar a um público invisível. Para outros, ainda, é instrumento de impetrar respeito. Ela é todas essas coisas porque não se pretende nenhuma delas. Nunca se consegue encontrar "o objetivo" da rádio como mote fundamental; talvez o mote seja dar vazão a tantas linhas de possibilidade quantas surgirem.

Guattari já contava acerca da posição das rádios livres da França quando o Estado interveio para legalizá-las e institucionalizar suas produções, na década de 1970 (GUATTARI; ROLNIK, 1999, p. 115): 
O que estamos a fim não é de fazer grandes rádios livres, mas de fazer nossas rádios livres. [...] Estamos pouco ligando para o índice de audiência, pois quem quiser que nos escute; se não, basta virar o botão. Queremos ser os únicos a garantir aquilo que nos agrada, aquilo que é nossa produção, sem nos referirmos aos novos tipos de julgamento da mídia.

As ações e os conflitos vividos no Potência Mental sugerem antagonizarse com a institucionalização pelo Estado e também pela própria militância. A única militância que se mostra possível tem como balizas a abertura ao que vier e a produção do diferente, não importa se algum diagnosticado quiser elogiar o manicômio ou ser contra o aborto, ou se achar vulgar a profissional do sexo entrevistada (casualmente, ou não, essas posições sustentaram-se em diagnosticados, todas as três vezes).

Cada uma dessas temáticas foi polêmica quando surgiu nas reuniões e programas, porque, para alguns, sugeria um discurso hegemônico de preconceito ou manutenção do estado de coisas cristalizado por parte dos diagnosticados, sendo contrário à proposta de produzir diferença. Dizendo "não importa", não queremos negar os conflitos que se estabelecem no Coletivo quando da contradição de posições, por vezes sugerindo a injunção de uma diferença específica e institucionalizada na militância por parte dos estudantes e profissionais do Coletivo. Justamente, os conflitos permitem relativizar a posição do hegemônico que, no processo da Rádio, faz-se diferença, e vice-versa, trazendo à baila a agitação que surge quando dessas polêmicas, apontando para a dimensão ética e plural da palavra que se força diante do encontro de discursos divergentes, forçando o Coletivo à sustentação de um espaço para "o que vier", assistindo ao surgimento de novos sentidos.

Essa multiplicidade de linhas de força que constitui o fazer rádio denuncia a dimensão coletiva do Potência Mental, e, como efeito da emergência de uma palavra plural, evitam-se os guetos e mudam-se as relações no próprio seio da rádio, como defende Guattari (GUATTARI; ROLNIK, 1999). Anuncia-se uma marca do Coletivo em questão. Muito da "tradição" nas rádios em saúde mental diz de uma insistência na importância de o programa ser produzido inteiramente pelas pessoas em situação de sofrimento psíquico, ou com história de tratamento psiquiátrico. $\mathrm{O}$ estranhamento que isso provoca faz sentir que, quanto mais se preze pela não contaminação dos profissionais e estudantes no programa, mais se dualizam os sujeitos e se mantém a dicotomia responsável pela discriminação dos "diferentes". A diferença que se força no Potência Mental é a inerente aos encontros, não aquela que se imprime a um rótulo qualquer. Por isso, como já aludimos, o uso do termo "diagnosticados", tomado da Rádio Nikosia para chamar alguns dos loucutores do Potência Mental, ao invés de "loucos" O que se pretende considerar é a marca da nosologia e do tratamento psiquiátrico que um diagnóstico imprime e que não é irrelevante; ao mesmo tempo, a ação de descolar a loucura das pessoas que supostamente a "incorporariam" permite à loucura transitar pelo Coletivo e por todos os seus (des)encontros disruptivos. 
Um dos efeitos dessa descolagem é o enunciar de que tanto os diagnosticados como os profissionais e estudantes (forjando novamente uma separação que jamais se consolida) são loucutores, configurando um espaço de fala para todos. O efeito disso, por sua vez, não é o de "dar voz" para os usuários dos serviços de Saúde Mental, "marginalizados e excluídos" - legitimando a reprodução desse modelo -, mas fazer falar o Coletivo, liberto de categorias e para além e aquém dos indivíduos e rótulos. Dá-se voz, assim, à multiplicidade que o constitui a cada momento e lhe permite constituir-se mídia menor.

Que essa multiplicidade possa tomar a palavra através da rádio aponta na direção de um alargamento nos modos de habitar a cidade, para o qual as tecnologias de comunicação passam a ser um importante intercessor, como dispositivo estratégico que permite alinhar a produção de conhecimento e os movimentos de luta por uma sociedade sem manicômios à produção de conhecimento e luta pela democratização dos meios de comunicação. Nesse contexto, as mídias comunitárias assumem papel estratégico junto aos movimentos de minorias; e, no tocante à radiodifusão, se as rádios comunitárias têm sido marcadas pela tendência a operar no âmbito de "micropolíticas identitárias e reivindicatórias de setores sociais específicos" (COGO, 2004, p. 45), observa-se a presença de práticas que se pretendem de resistência atuando na via da desterritorialização - vide as ações das rádios livres, intervindo com ou sem "permissão". (STREPPEL, GORCZEVSKI, PALOMBINI, 2010).

O Coletivo é lançado, assim, ao ansiado risco de abdicar de estruturações. Sem coordenador, sem pauta, sem grade; ou melhor, sempre digladiando com esboços de última hora do que sejam essas estruturações. Não que isso tenha sido uma escolha, porém, algo parece sempre puxar para fora, para o Fora, nesse movimento enlouquecedor de falar todos ao mesmo tempo e muito improvisar, marca de devir-loucura desse Coletivo.?

\section{A BORDO dO DIÁRIO DE BORDO}

Chego e encontro duas mesas unidas no bar, abarrotadas de gente, e abarrotadas de barulho - sim, porque barulho também ocupa espaço. Puxo uma cadeira e me sento, atônita com o que parecia uma grande bagunça. Alguém permanece repetindo, depois de mais de uma hora de iniciado o papo: "Quando vai começar a reunião?", e aquela pergunta ecoa ao infinito. Quase sinto vontade de sintonizar o Coletivo como se fosse um aparelho de rádio, mas logo esqueço quando ouço uma voz: "Bate essa foto pra nós?". E o pessoal começa a se despedir, está na hora de ir embora. Alguém pergunta: “Acabou a reunião?”. Outro responde: "Nem começou, mas pelo jeito já acabou".

Tudo isso pra dizer que aquele sentimento de desorganização me toma novamente, mas também eu estou mergulhada no turbilhão. Mas parece inevitável me deparar com 
uma das dificuldades desse trabalho: às vezes parece que nada acontece! E eu sinto no corpo, por vezes, o peso da responsabilidade de sustentar um espaço de acolhimento e de criação, mas eu não quero sustentar nada, não consigo sustentar, meu corpo magro esmaece com o peso do nada acontecer. Eu quero é fazer rádio, contemplar a criação artística, cultural e comunicacional. Inventar sentidos, mas naquilo tudo que a invenção tem de impessoal, naquilo que ela não depende da nossa vontade.

Mas esse mesmo corpo magro, talvez justamente por não sustentar nada, pode agenciar acontecimentos. Lembro agora daquele programa sobre hábitos alimentares, quando o Valdir ${ }^{8}$ retoma o tema das simpatias, ensinando especialmente uma delas, que resolveria dois dos nossos problemas de uma só vez. Eu, me considerando magra, e o Felipe, se considerando gordo. Fácil, basta eu comprar dele quantos quilos eu quiser, custando R\$ 0,08 o quilo. Compro cinco.

Alguns dias depois, o (in)esperado. A balança torna-se dispensável, é visível a perda de peso do Felipe. E as atenções agora se voltam para mim. Onde foram parar os quilos que ele me passou? Eu continuo com o mesmo corpo magro de sempre, parece que os quilos se perderam no caminho. Dobraram a esquina errada, tomaram outra direção, voaram ao sabor do vento. Passados mais de três meses, eles parecem já nem lembrar mais o caminho de volta, gostaram mesmo do sabor do vento. Mas o Valdir, nosso guru, não desiste. Quase todo encontro ele me pergunta o que eu ando comendo, me dá sugestões de cardápios, me indica outras simpatias para complementar, pede para que eu oriente o pensamento para encontrar os quilos que não me encontraram. A insistência do vento se manifesta não por acaso através do nosso guru; esse vento desvairado que enfeitiçou os quilos que se negam a prender-se novamente, libertos que foram da prisão corporal do Felipe, esse guru aberto ao inapreensível. A palavra atuou no corpo do Felipe, que reagiu liberando um "algo" que insiste em não se reduzir a um efeito corporal em mim, promessa que é de uma sempre possível efetuação futura e passada, ao mesmo tempo, esquecimento e espera. Algo que se desprende dos corpos, de suas impressões e afecções. Com isso tudo, o mesmo corpo magro que sofre em sustentar um espaço instável de trabalho pode fazer jorrar ao vento justamente tudo aquilo que não consegue assimilar e assim agenciar essa instabilidade em potência de criação rizomática.

E por falar em rizomático, volto ao problema da organização, e me remeto a um programa sobre diversidade. Muitas das 
pessoas que propuseram o tema não estiveram presentes, e já é notório que não posso dizer que a sensação de desamparo que vivenciamos seja rara. E talvez seja algo do nosso motor de criação. Digo isso porque este programa acaba sendo um dos mais divertidos. Mistura-se fala, música, telefonema, problemas técnicos, silêncio no ar, gargalhadas; e assim temos a efetuação daquilo que seria o tema do programa, a expressão realizando o conteúdo. A diversidade nua e crua dispensando qualquer designação. Uma gargalhada e uma frase escapam da minha boca como se eu não tivesse muito controle sobre ela - nem sobre a boca, nem sobre a frase: "Esse programa foi a cara do Potência Mental!"

Mas para minha surpresa, o assunto posterior, fora do estúdio, é a "qualidade" do programa. Parece-me que novamente está sendo colocada na roda a questão da nossa organização, da "estruturação" do programa, ou como queiramos chamar, "porque temos que ter mais qualidade no que produzimos". Mas a vantagem da "organização" é poder ser desafiada, e isso é importante.

É interessante o conflito sempre presente referente ao quanto devem ser planejados e bem preparados os nossos programas. Quando conheci o Coletivo de Rádio Potência Mental, ele parecia tão forte, tão bem organizado! O que eu talvez não soubesse era que força e organização não são sinônimos. $O$ Coletivo sugere resistir a qualquer tentativa de estruturação, a tal ponto de quase nada parecer funcionar. Mas há uma coisa que sempre acontece: os programas e as reuniões sempre acontecem. E neles, o que acontece é a conversa, a fala. Nosso fazer é a fala, e isso não é irrelevante. É a fala em todo seu turbilhão que percorre todos os mundos, como se o barco que move nossa criação navegasse outros caminhos que não levam [...] a lugar algum. Talvez nosso caminho não pretenda chegar a nenhum lugar, talvez seja um caminho sem caminho.

Isso porque a força e a Potência do Coletivo em questão não se atrelam à sua organização, e às vezes até me atrevo a pensar que possam se atrelar em alguma medida justamente à sua desorganização, ao imprevisto e ao improviso que, como eu dizia, dão medo e alegria. Aquele medo e aquela alegria que só a surpresa é capaz de provocar, porque não depende da nossa vontade, e que vai acontecer ou deixar de acontecer ao gosto do vento.

...Ao gosto do vento... Tal qual a fumaça do cigarro doValdir, nossas vozes, nas reuniões no bar e nos programas, querem 
se misturar ao vento, incomodar quem não concorda com elas, ressoar indefinidamente.

A potência da não-diretividade é também o risco do esfacelamento. É a razão do medo. A não-atividade e a fala que age não garantem que haja ação sempre, não asseguram a invenção de sentidos sempre, afinal, não haveria a parceria entre medo e alegria se a invenção alegre fosse certa. Não é confirmada, calma nem pacífica uma produção que começa quando termina, tal qual nossas reuniões. ${ }^{9}$

\section{UMA PRODUÇ̃̃o LOUCA}

Como dissemos, no trabalho do Coletivo de Rádio Potência Mental, o estatuto da loucura sempre pareceu se constituir uma questão importante. É como se o desejo fosse o de encontrar uma loucura enquanto modo de vida que fosse uma espécie de bolsão do Fora, passível de trazê-lo constantemente na língua, e o de que a presença de "loucos" no rádio fosse garantia da diferença na comunicação, tal qual Foucault argumentava nos primeiros avanços de sua obra (PELBART, 2002). Mas não é bem assim.

Não é assim quando a nosologia psi torna-se questionável; não é assim quando o diagnóstico não dá conta de construir efetivamente uma categoria diversa dos não-diagnosticados; e, finalmente, não é assim quando a veiculação de discursos de diferença parece vir mais dos estudantes do que desses que gostaríamos que nos salvassem das garras do hegemônico e nos trouxessem a fluidez de uma língua sem prisões.

Silva (2005), pensando com Castel, entende que as estratégias pós-sociedade disciplinar acabam por produzir loucos adaptados, ao invés de transgressores, porque, antes de focalizar na correção dos desvios, investe na programação da eficiência e na gerência da vida humana, através de psicofármacos e novos dispositivos de tratamento. Assim, a possibilidade de circulação pela cidade, que é o caso dos diagnosticados que participam da rádio, talvez esteja relacionada justamente a uma adaptação aos discursos hegemônicos.

Essa conjuntura à parte, a loucura ainda deixa de ser garantia de produção de diferença à medida que, mais do que agenciar acontecimentos por ser acesso ao Fora, pode afundar-se nele e produzir apenas horror, pela impossibilidade de constituir uma superfície onde acontecimentos possam inscreverse (DELEUZE, 1997, 2007).

O Fora é sim possibilidade de trazer o impensado ao pensamento e o indizível ao discurso, mas sob a condição da superfície-limite onde a diferença possa se manifestar sem sucumbir ao horror, onde possa operar acontecimentos. (DELEUZE, 1997; PELBART, 1989). Pois, para Deleuze (1997; 2007), a loucura remeteria a uma agramaticalidade caótica, a fragmentos fonéticos (ou discursivos) que não 
se relacionam e afetam diretamente o corpo sem constituir a superfície necessária ao sentido. Não seria capaz de traduzir um acontecimento ${ }^{10}$ que salta dos corpos para manter-se enquanto virtualidade sempre esquecida e sempre à espera.

A loucura-puro-Fora toma, no entanto, tal forma na Rádio que é capaz de produzir acontecimentos na medida em que expressa uma linguagem que atinge e desafia os corpos no instante mesmo em que se diz e se contradiz, atuando sob a lógica da diferença: ${ }^{11}$ emergem assim, por exemplo, o acolhimento em um manicômio impessoal, uma elegância no flerte com a vulgaridade de uma profissional do sexo, uma "agri”cultura musical e poética, e até uma simpatia que surrupia dinheiro e quilos...

A partir disso tudo, o estatuto da loucura no Potência Mental passa a ser questionado. Onde estaria a loucura que, em última instância, é a agenciadora deste trabalho com rádio? Para além e aquém de qualquer loucura suposta a alguns loucutores, viu-se um Coletivo tomado por um extremo de não-senso, um paradoxo que insiste em produzir através dessa instância caótica de anti-produção que é o corpo-sem-órgãos ( $\mathrm{CsO})$ da loucura, como uma quase-causa de onde emana a produção de produção (DELEUZE; GUATTARI, 2004, 2006, 1996).

O CsO é descrito, pois, em Mil platôs, como um exercício, "uma experimentação inevitável" (DELEUZE; GUATTARI, 1996, p. 9). Povoado apenas por intensidades, é o que em nós se opõe, não aos órgãos, mas à sua organização, a que chamamos de organismo: "O organismo não é o corpo, o $\mathrm{CsO}$, mas um estrato sobre o $\mathrm{CsO}$, quer dizer um fenômeno de acumulação, de coagulação, de sedimentação que lhe impõe formas, funções, ligações, organizações dominantes e hierarquizadas, transcendências organizadas para extrair um trabalho útil" ((DELEUZE; GUATTARI, 1996, p. 21). O CsO oscila, assim, entre as estratificações que o constrangem e a experimentação a que se lança desfazendo os estratos e liberando os fluxos. Ele é o campo de imanência do desejo, ao qual nunca se acaba de chegar, pois é como devir que se realiza (PALOMBINI, 2007) - antiprodução, portanto, produtora de produção.

Essa instância loucura-corpo-sem-órgãos é, portanto, o que faz superfície para que se inscreva uma produção, em constante relação com uma dimensão de indefinição. E a loucura na Rádio, assim, jamais estava onde procurávamos. Não estava na garantia de produção de diferença sob nenhum aspecto, aliás, não era nem mesmo capaz de se apresentar como categoria. No entanto, estava sempre ali, produzindo agenciamentos, enovelando-nos uns aos outros e à produção em rádio e produzindo sentidos, paradoxalmente, em meio ao caos. A loucura-corpo-sem-órgãos pode ser pensada como a carta roubada de Edgar Allan Poe, trabalhada por Lacan (1998) e que Deleuze (2007) comenta: mimética com a paisagem, fica invisível e falta em seu próprio lugar. A loucura jamais aparece, embora também não se esconda. A ausência a seu próprio lugar é que justamente faz possível a circulação de sentidos. A loucura seria, assim, o não-engendrado ou caótico que serve de superfície para o registro de processos de produção do desejo (DELEUZE; GUATTARI, 2004). Esta é a possibilidade de exterioridade trazida por Pelbart (2002), a possibilidade de pensar diferente- 
mente, de inserir o impensável no pensamento e o indizível na palavra. Assim, o Fora se dissolve num modo esquizo generalizado, assumido pelo Coletivo de Rádio na medida em que funciona sob o que chamamos de devir-loucura. Disso decorre o limite tênue característico da doença mental, como defendido por Deleuze e Guattari (2006), limite que separa a transgressão produtiva do desabamento iminente, e, acrescente-se, da desarticulação total do trabalho da rádio, conforme referido acima, no diário de bordo - medo por vezes presente no Coletivo, em decorrência do sentimento de caos.

Quanto à noção de Fora, segundo Levy (2003), ela surge no início do séc. $\mathrm{XX}$, no universo da literatura, com a superação do paradigma clássico da representação, abalando as noções de realidade, autor, linguagem, pensamento e experiência. Blanchot cria o conceito para dar conta das novas relações da literatura com a realidade, sustentando-o no paradoxo da realização pela irrealização e na negação e ausência do objeto do qual se fala e do eu que fala, à medida que a linguagem teria uma materialidade que não se reduz a uma propriedade dos objetos sobre os quais se fala e nem do sujeito que fala. Foucault (2001b; 2001a; DELEUZE, 2005) apropria-se do conceito para anunciar justamente o desaparecimento do autor e a materialidade do ser da linguagem, ${ }^{12}$ além da possibilidade de engendrar resistência pela subjetivação. Deleuze, por sua vez, introduz a noção para pensar a linguagem mas também o próprio pensamento e a vida enquanto potência de criação a partir do plano de imanência, crivo que agencia o caos, ou Fora (DELEUZE, 1997, 2005, 2002; DELEUZE; GUATTARI, 1992, 1995a, 1996). É difícil definir esse conceito, tão amplamente tematizado por autores tão importantes, em diferentes contextos. Torna-se ferramenta para nós à medida que o façamos funcionar como o outrem absoluto, constituído de intensidades selvagens que se responsabilizam por inserir singularidades não formadas que, no entanto, constituem as formas.

Enfim, o CsO do Coletivo de Rádio que permite estar em constante contato com o Fora implica noções de loucura e inconsciente como usinas de produção, praticando um giro em torno de um centro sempre descentrado, operando a emergência de uma obra sempre inacabada através de seu constante desfazimento:

- A ausência de obra, um outro nome para a loucura.

- A ausência de obra onde cessa o discurso, para que venha, fora da palavra, fora da linguagem, o movimento de escrever atraído pelo exterior. (BLANCHOT, 2001, p. 72)

\section{UM DISCURSO LOUCO}

A produção de inscrição operada pelo $\mathrm{CsO}$ se aproxima precisamente ao acontecimento. Apostamos numa acontecimentalização ${ }^{13}$ do programa de rádio sustentado por um produto - a fala - que remete ao materialismo do incorporal do ser da linguagem, garantido pelo acontecimento que o torna possível. Deleuze (2007, p. 188) já dissera acerca da linguagem: “[...] tudo isso não seria senão barulho sem o acontecimento e barulho indistinto". 
O CsO é como o barulho que engendra acontecimento enunciativo e "designa sempre esta realidade intensiva, não indiferenciada, mas onde as coisas, os órgãos, se distinguem unicamente por gradientes, migrações, zonas de vizinhança" (DELEUZE; GUATTARI, 1996, p. 27). Estudantes que buscam discursos "novos" e diagnosticados que trazem discursos chamados "hegemônicos". A ditadura do novo e a subversão pela via do hegemônico. Loucura desencontrada, caos que produz: eis nosso terreno. Os órgãos, os corpos ou os significados - e também a loucura, a diferença e produção - não existem enquanto unidades prontas, senão como não mais que "ensaios" de totalidades, jamais fechadas em si, atravessadas umas pelas outras, feitas intensidades. O CsO, "feito de tal maneira que ele só pode ser ocupado, povoado por intensidades" (DELEUZE; GUATTARI, 1996, p. 13), é superfície de plena produção de diferença no plano de imanência. É desafio simultaneamente ao horror do afundamento no puro "Fora e ao" universo cristalizado das significações que se digladiam no diálogo. É a loucura produtora de sentido, enfim.

Contrário à cristalização de significados prontos de uma vez por todas, esse corpo-sem-órgãos se produz justamente por afectos. Intensidades libertas das afecções dos encontros das reuniões da Rádio onde impera o barulho das vivências e as significações prontas, os afectos permitem acessar as virtualidades responsáveis pelo acontecimento que transforma o barulho em sentido. Permitem fazer saltar para além da significação e do caos. "O afecto não é a passagem de um estado vivido a um outro, mas o devir não humano do homem", afirmam Deleuze e Guattari (1992, p. 224); aquilo que nos põe em contato com o inumano, com o que é da ordem da impessoalidade do acontecimento que não acontece "a alguém ou por alguém", simplesmente acontece. Devir do encontro de discursos, circuito de intensidades que compõem o corpo-sem-órgãos. Devir-diferença do preconceito, devir-gordura da palavra, devir-vento da magreza, devir-loucura no rádio. (DELEUZE; GUATTARI, 1996, 1992; DELEUZE; PARNET, 1998)

É nesse sentido que se aposta num fazer Rádio que agencie a produção de línguas menores ${ }^{14}$ diante do contato de discursos desencontrados (GUATTARI, 2005; GUATTARI; ROLNIK, 1999). É o entrecruzamento da materialidade da linguagem com o estatuto da loucura no Potência Mental.

Eis então o que seria necessário fazer: instalar-se sobre um estrato, experimentar as oportunidades que ele nos oferece, buscar aí um lugar favorável, eventuais movimentos de desterritorialização, linhas de fuga possíveis, vivenciá-las, assegurar aqui e ali conjunções de fluxos, experimentar segmento por segmento dos contínuos de intensidades, ter sempre um pequeno pedaço de uma nova terra. (DELEUZE; GUATTARI, 1996, p. 24)

A atitude de acolher também o que sugere ser discurso hegemônico ainda garante que a loucura mantenha-se em devir, ou seja, que o Coletivo nunca se identifique a ela em sua face de horror e caos puro. Deleuze (1997) já dizia que devir é afetar-se pela vizinhança, habitar o "entre" e o limite que justamente o 
coletivo $^{15}$ de forças que é o CsO possibilita quando agencia intensidades selvagens num "Continuum ininterrupto do $\mathrm{CsO}$. O CsO, imanência, limite imanente" (DELEUZE; GUATTARI, 1996, p. 15).

Em Deleuze e Parnet (1998) também se encontra o devir como o espaço "entre" de uma conversa. Conversa que, no caso da Rádio, é a negociação entre os diversos discursos que surgem em seu fazer, que jamais se sintetizam num outro totalizado, mas conversam entre si e transformam-se. Há apenas "entre". O que o funcionamento esquizo do Coletivo engendra é um resultado inusitado, que não estava em nenhum dos discursos, mas que se produziu no encontro.

Blanchot (2001) também fala da conversa, referindo que a potência do encontro de duas palavras é justamente a possibilidade de ambas serem falantes e se ligarem a partir do desnível intrínseco ao diálogo, a partir de sua diferença. $\mathrm{O}$ efeito desse processo seria a emergência de uma palavra plural, que resguarda toda a potência da ruptura e da fuga. Palavra plural que é devir.

Palavra plural que é o efeito de uma produção caótica que faz acontecimentalizar. Efeito de um coletivo composto por "loucutores", feito louco de si mesmo à medida que subverte o estatuto da loucura e os próprios discursos veiculados, pela via do encontro. Por tudo isso, os paradoxos que fazem funcionar a produção de sentidos na Rádio Potência Mental fazem dela uma "Alice”. Guattari (2005) já comemorava a insistência de "Milhões e milhões de Alices no ar" quando o nome Alice era sinônimo de rádio-linha-de-fuga, como pretendemos também ser. Com Deleuze (2007), o Potência Mental se aproxima da personagem Alice de Lewis Carroll, confrontada, como nós, com paradoxos insolúveis que lhe confundem a respeito de sua própria identidade e a carregam por um caminho-sem-caminho que a leva, e também a nós, a deslizar na superfície do espelho e do acontecimento.

\section{E A PESQUiSA DEVÉM-COLETIVO, DEVÉM-LOUCURA...}

Como se nota, a estratégia fundamental da pesquisa foi a de compor o Coletivo, compreendido nos termos em que nos fala Guattari (1992, p. 20), como uma "multiplicidade que se desenvolve para além do indivíduo, junto ao socius, assim como aquém da pessoa, junto a intensidades pré-verbais, derivando de uma lógica dos afetos mais do que de uma lógica de conjuntos bem circunscritos". Mais do que um agrupamento humano, o mesmo é constituído de instâncias humanas e não humanas, especialmente por singularidades que aparecem como discursos impessoalizados e afectos que mobilizam as identidades, fazem relacionar, questionam e se delineiam como forças na composição dos agenciamentos que vão desenhar os movimentos da pesquisa.

A escrita de um diário de bordo ${ }^{16}$ serviu como um exercício de cartografia do movimento dessas forças expressivas das singularidades e intensidades que se encontram (ou não) e se agenciam (ou não) no processo, pela via do registro das percepções e afecções da pesquisadora. Deleuze e Guattari (1995a) defendem a cartografia como própria ao rizoma, pois se trata de uma possibilidade de se mapear as forças, encontros, devires e virtualidades de modo que se possam conectar 
essas intensidades umas às outras sob todas as dimensões do mapa, entrando por qualquer lado, abolindo todo tipo de centralização e promovendo mudança e reconstrução constantes. É como a produção mapeando-se a si mesma, o produtor incluindo-se no mapa a partir da libertação de suas singularidades, impessoalizando-se e entregando-se completamente às forças em movimento.

Atingir a dissolução do pesquisador no campo diz de assumir a indissociação sujeito-objeto como primeira e as pessoas gramaticais como efeito de pesquisa. Passos e Eirado (2009) defendem que reconhecer a performatividade da experiência é condição para a dissolução do ponto de vista de observador, uma vez que legitima a coemergência eu/mundo na experiência.

No presente caso, pareceu inevitável, sentimo-nos sucumbir ao Coletivo quando não nos sentimos mais donos de nossa própria voz, contaminada pelas vozes dos outros participantes, pelas múltiplas vozes em nós: pesquisadora, participante do Coletivo, loucutora, etc. Sujeito e objeto, ou pesquisadora e Coletivo de Rádio, confundem-se na mesma massa informe de onde emergem as formas programa de rádio, problema de pesquisa e mesmo o presente texto.

"O sujeito é uma variável, ou melhor, um conjunto de variáveis do enunciado. [...] Assim, o que é primeiro é um 'diz-se', murmúrio anônimo no qual posições são apontadas para sujeitos possíveis", diria Deleuze (2005, p. 64), acerca do pensamento de Foucault. Desse "diz-se", agenciador de vozes-discursos e sujeitos-objetos, extrai-se a quarta pessoa do enunciado, que, tal qual o on do idioma francês, faz encontrar o singular, a curva de singularidades que constitui, acontecimentaliza e provê sentido ao enunciado. (DELEUZE, 2005; SCHÉRER, 2000)

O principal efeito de se perseguir a quarta pessoa na pesquisa é o caminho que se força na direção dos agenciamentos coletivos de enunciação, cujo tecido enredado com/entre as forças insistentes no plano do coletivo constitui os pressupostos implícitos da linguagem e a condição da mesma em sua materialidade, porque condição da doação de sentido. Constitui sua dimensão ilocutória, capaz de permitir à linguagem redundar num ato, ou ser performativa, como Deleuze e Guattari (1995b) bem aprendem com Austin.

Linguagens radiofônica e acadêmica que se fazem experiências performativas engendrando realidades, misturas de coisas, sujeitos e objetos. Intervenção, a linguagem faz, dos agenciamentos coletivos do Potência Mental que a produzem como ato no mundo, importante dispositivo de pesquisa.

Coletivo-dispositivo que, tal qual o grupo-dispositivo de Barros (1997), permite o encontro com outrem. Mais (ou menos) do que o encontro com o outro, a noção de coletivo abre caminho ao desconhecido como modo de experimentar, porque, uma vez multiplicidade de intensidades, promove a transição do "outro", ao nível molar pessoal, ao "outrem", molecular e intensivo. "Outrem" agenciado por essa composição de linhas de perturbações no coletivo que forçam o pensamento em direção ao impensado, abrindo-se assim à alteridade radical que Blanchot denomina o Fora (LEVY, 2003). 
Assim, o "entre" da conversa e da palavra plural engendrada no Potência Mental agora pode ser pensado em termos de coletivo, uma vez que, como o grupo de Barros (2007), o coletivo do encontro com "outrem" é justamente o coletivo do "entre". A suposta unidade-totalidade grupal se esvai diante desse modo de experimentar desde "outrem", desde o movimento provocado por esse espaço diferencial "entre" os fluxos que correm no coletivo, produzindo devires e faíscas que saltam do atrito "entre" corpos; faíscas que não pertencem nem a um corpo nem a outro; devires não identificados nem à vespa nem à orquídea, pois enxertam intensidades de vespa à orquídea e vice-versa, para usar o célebre exemplo de Deleuze e Guattari (1995a). O coletivo do "entre" é, assim, o coletivo dos afectos como devires e dos sentidos como faíscas.

Em seus movimentos de devir-loucura, o CsO que constitui o Potência Mental não permite muito mais do que devires. Assim, mais (ou menos) do que um grupo de rádio, o mesmo apresenta-se como um Coletivo e, portanto, um dispositivo.

Mas por quê? “O que é um dispositivo?”, Deleuze (1996, p. 1) pergunta acerca desse constructo de Foucault. E segue respondendo, a si mesmo e a nós: "É antes de mais uma meada, um conjunto multilinear, composto por linhas de natureza diferente"(DELEUZE, 1996, p.1) Máquinas de fazer ver, falar, máquinas de poder e de subjetivação, os dispositivos se definem pela dimensão multilinear coletiva com que se redesenham enquanto suas linhas se inter-relacionam, resistindo e rompendo-se sempre em favor de dispositivos futuros. Sua filosofia engloba o "repúdio dos universais" e "uma mudança de orientação que se desvie do Eterno para apreender o novo", mas "como é que é possível no mundo a produção de qualquer coisa de novo" (DELEUZE, 1996, p. 3)?

No que se refere à enunciabilidade, nosso interesse radiofônico e acadêmico,

É verdade que Foucault, em toda sua teoria da enunciação, recusa explicitamente a "originalidade" de um enunciado, como critério pouco pertinente, pouco interessante. Foucault pretende somente considerar a "regularidade" dos enunciados. Mas, o que ele entende por regularidade é a linha da curva que passa pelos pontos singulares, ou valores diferenciais, do conjunto enunciativo [...] o que conta é a novidade do próprio regime de enunciação que pode compreender enunciados contraditórios. (DELEUZE, 1996, p. 3-4)

Assim, diante dos regimes ou linhas de enunciação em constante (re)(des) fazimento através do encontro louco de vozes múltiplas e discursos contraditórios, tendo como forma o informe e como contorno o devir-loucura, o dispositivo Coletivo de Rádio em questão, máquina de fazer falar, faz-se sua própria fenda em direção a um dispositivo futuro, faz-se seu próprio Fora.

Isso implica dizer que a reintrodução do Fora no centro do pensamento e da palavra surge como efeito do processo de um devir-loucura engendrado por um Coletivo cartografado por uma pesquisa que é nada mais e nada menos do que efeito desse mesmo processo. Mais (ou menos) do que sujeito e objeto de pesquisa indis- 
sociados, o coletivo, dispositivo de produção de mundos outros de enunciabilidade, faz-se, agora, também método de pesquisa. Método-dispositivo que possibilita enunciar, acerca de si próprio, um estatuto de loucura (devir-loucura) que se descola da doença mental para se espraiar por todos os "entres", "ao gosto do vento... Tal qual a fumaça do cigarro do Loucutor V. [e] nossas vozes, [que] querem se misturar ao vento, incomodar quem não concorda com elas, ressoar indefinidamente".

\section{Notas}

Valemo-nos aqui da leitura que Deleuze (2005) propõe do conceito de Fora com que trabalha Foucault, enfatizando, em especial, a determinação do fora como força, expressa em fluxos desordenados e intempestivos que constituem singularidades de resistências aos poderes e saberes instituídos. O fora, como distância, como diferença da qual resulta o enfrentamento de forças, é então situado num espaço entre os dois regimes - o do visível e o do dizível - em que se estratificam as formas (saber), no aprofundamento da fissura entre as palavras e as coisas, e mais além dos diagramas em que as forças operantes nos estratos são presas (poder), preservando, assim, um potencial de resistência ao poder e, portanto, a capacidade de afetar os diagramas e seus agenciamentos concretos (PALOMBINI, 2007). Retornaremos a esse conceito mais adiante, no corpo do texto.

2Trata-se da dissertação de mestrado de Fernanda Streppel, orientada por Ana Alice Palombini, defendida em 01 de abril de 2011, sob o título Potência mental no ar... exercícios de esquizoradiofonia. (STREPPEL, PALOMBINI, 2011). Disponível em: < http://www.lume. ufrgs.br/handle/10183/29678>.

Embora a sede da Rádio Nikosia seja a Rádio Contrabanda FM, a mesma denomina-se uma "emissora transversal", pois se utiliza de vários canais de comunicação para a difusão de uma palavra emitida pela perspectiva da loucura (CORREA-URQUIZA, 2009). Participa com intervenções semanais em outras duas rádios da Espanha, mantém vários fóruns online, participa de produções de vídeo, realiza palestras e publicou um livro, dentre outras intervenções. Para saber mais, visitar: http://radionikosia.org, http://www.radionikosia.blogspot.com, http://nikosia. contrabanda.org.

${ }^{4}$ Residência Multiprofissional vinculada ao Ministério da Saúde em parceria com a Fundatec, em Porto Alegre/RS/Brasil, atualmente referida à Universidade Federal do Rio Grande do Sul.

Como se nota, o termo "loucutores" é adotado pelo Coletivo Potência Mental, mas já era utilizado pela Rádio Tam Tam, bem como pela Maluco Beleza, de Campinas. No presente caso, refere-se a todos os participantes, diagnosticados ou não.

"Os projetos “Oficina de Imagens", de produção de vídeos, e "Oficinando em Rede”, de informática e produção de blogs, juntamente com o projeto "Coletivo de Rádio", compõem o Programa "Rede de Oficinandos: Tecnologias de Informação e Comunicação Produzindo Inserção Social, Cuidado e Formação em Saúde Mental" contemplado pelo Edital Proext 2009.

O Coletivo tem um blog onde publica os programas gravados: http://potenciamental.blogspot. com. O e-mail para entrar em contato é potenciamental@yahoogrupos.com.br.

Os nomes próprios referem-se a formas escolhidas pelos próprios participantes da Rádio.

${ }^{9}$ Trechos de um relato que compõe a dissertação em construção em torno da produção do Coletivo, modificados a fim de que possam se adaptar ao presente texto e às discussões em foco.

${ }^{10}$ Em Deleuze (2007), o acontecimento é algo no que acontece, é o expresso do acidente que acomete as coisas e os corpos, é o que resta para além da efetuação cuja grandeza é justamente o sentido. É um incorporal, constituído de singularidades liberadas dos limites da sua atualização corporal.Produz, assim, sentidos sempre localizados numa superfície que une e separa o mundo dos corpos cristalizados do mundo das palavras idealizadas.

${ }^{11}$ A diferença é um conceito-chave em Deleuze, tão mais potente à medida que não se o represente. Se trata justamente do avesso do pensamento da representação e da reversão do platonismo pela via da afirmação de uma diferença que é primeira em relação ao modelo (SCHÓPKE, 2004).

${ }^{2}$ Sobre o materialismo do incorporal, dimensão da linguagem que lhe confere o estatuto de acontecimento e de existência independente das coisas sobre as quais intervém, ver FOUCAULT, 2009; 1999; 1972; 2001a; 2001b; 2002; entre outros textos.

${ }^{3}$ O termo "acontecimentalizar" é pego de empréstimo de Fonseca et al (2006), quando defendem a proposta de Foucault de "acontecimentalizar a pesquisa". 
${ }^{14} \mathrm{O}$ termo "menor" não se refere a tamanho nem quantidade, mas a potência de desestabilização do pronto, do cristalizado, do já instituído. "Língua menor" é, para Deleuze e Guattari (1995b), mais do que um idioma, uma espécie de dialeto que se utiliza das "línguas maiores" ou oficiais para produzir diferença desde e sobre as mesmas. Para nós, o termo serve como metáfora dos "novos" discursos que surgem no Potência Mental desde uma renovada maneira de utilizar os usuais ou hegemônicos.

"A partir de agora, utilizaremos o termo "coletivo", com inicial minúscula, para nos referirmos à noção de "coletivo de forças", diferenciando-o do termo "Coletivo", com inicial maiúscula, utilizado para nos referirmos ao "Coletivo de Rádio" em questão.

${ }^{16}$ A utilização da expressão "diário de bordo" provém de Barros e Passos (2009, p. 172).

\section{REFERÊNCIAS}

ASSOCIAÇÃO PROJETO TAM TAM. Nossa história. Disponível em: <http:// www.tamtam.art.br/ong/?pagina=nossahistoria>. Acesso em: 10 dez. 2009.

BARROS, R. D. B. Dispositivos em ação: o grupo. In: SILVA, A. E. et al. (Org.). SaúdeLoucura 6. São Paulo: Hucitec, 1997. p. 183-191.

BARROS, R. D. B. Grupo: a afirmação de um simulacro. Porto Alegre: Sulina, 2007.

BARROS, R. B.; PASSOS, E. Diário de bordo de uma viagem-intervenção. In: PASSOS, E.; KASTRUP, V.; ESCÓSSIA, L. (Org.). Pistas do método da cartografia: Pesquisa-intervenção e produção de subjetividade. Porto Alegre: Sulina, 2009. p. 172-200.

BLANCHOT, M. A conversa infinita - a palavra plural. São Paulo: Escuta, 2001.

CAIAFA, J. Comunicação da diferença. Revista Fronteiras: estudos midiáticos, São Leopoldo, v. 1, n. 2, p. 47-56, jul./dez. 2004.

CHAO, M. La Colifata. Disponível em: <http://www.manuchao.net/manuchao/ la-colifata/index.php>. Acesso em: 10 dez. 2009.

COGO, D. M. Mídias, identidades culturais e cidadania: sobre cenários e políticas de visibilidade midiática dos movimentos sociais. In: PERUZZO, C. M. K. (Org.). Vozes cidadãs - Aspectos teóricos e análises de experiências de comunicação popular e sindical na América Latina. São Paulo: 2004. p. 41-56.

CORREA-URQUIZA, M. Radio Nikosia: La rebelión de los saberes profanos - otras prácticas, otros territorios para la locura. 2009. Tese (Doutorado)Universitat Rovira i Virgili, Tarragona, 2009.

DELEUZE, G. A Imanência: uma vida... Revista Educação e Realidade, Porto Alegre, v. 27, n. 2, p. 10-18, jul./dez. 2002. 
DELEUZE, G. Crítica e Clínica. Rio de Janeiro: 34, 1997.

DELEUZE, G. Foucault. São Paulo: Brasiliense, 2005.

DELEUZE, G. Lógica do Sentido. São Paulo: Perspectiva, 2007.

DELEUZE, G. O que é um dispositivo. In: . O mistério de Ariana. Lisboa: Veja, 1996. Disponível em: <http://www.prppg.ufes.br/ppgpsi/files/textos/ Deleuze $\% 20-\% 200 \% 20$ que $\% 20 \%$ C3\%A9\%20um\%20dispositivo.pdf>. Acesso em: 15 jan. 2010.

DELEUZE, G.; GUATTARI, F. Capitalismo e esquizofrenia. In: DELEUZE, G. A ilha deserta: e outros textos. São Paulo: Iluminuras, 2006. p. 295-305.

DELEUZE, G.; GUATTARI, F. Mil Platôs I Capitalismo e Esquizofrenia. Rio de Janeiro: 34, 1995a.

DELEUZE, G.; GUATTARI, F. Mil Platôs II Capitalismo e Esquizofrenia. Rio de Janeiro: 34, 1995 b.

DELEUZE, G.; GUATTARI, F. Mil Platôs III Capitalismo e Esquizofrenia. Rio de Janeiro: 34, 1996.

DELEUZE, G.; GUATTARI, F. O Anti-Édipo: capitalismo e esquizofrenia 1. Lisboa: Assírio Alvim, 2004.

DELEUZE, G.; GUATTARI, F. O que é a filosofia? Rio de Janeiro: 34, 1992.

DELEUZE, G.; PARNET, C. Diálogos. São Paulo: Escuta, 1998.

FONSECA, T. M. G. et al. Pesquisa e acontecimento: o toque no impensado. Psicologia em Estudo, Maringá, v.11, n. 3, p. 655-660, set./dez. 2006.

FOUCAULT, M. A Arqueologia do Saber. Petrópolis: Vozes, 1972.

FOUCAULT, M. A linguagem ao infinito. In: . Ditos \& Escritos 3: Estética - Literatura e Pintura, Música e Cinema. Rio de Janeiro: Forense Universitária, 2001a. p. 47-59.

FOUCAULT, M. A Ordem do Discurso - L'Ordre Du Discours, Leçon inaugurale ao Collège de France prononcée le 2 décembre 1970. 18. ed. São Paulo: Loyola, 2009.

FOUCAULT, M. As palavras e as coisas: uma arqueologia das ciências humanas. 8. ed. São Paulo: Martins Fontes, 1999. 
FOUCAULT, M. O Pensamento do Exterior. In: . Ditos \& Escritos 3: Estética: Literatura e Pintura, Música e Cinema. Rio de Janeiro: Forense Universitária, 2001b. p. 219-242.

FOUCAULT, M. O que é um autor? 5.ed. Alpiarça: Vega, 2002.

GUATTARI, F. Caosmose: um novo paradigma estético. São Paulo: 34, 1992.

GUATTARI, F. Milhões e milhões de Alices no ar. In: MEDITSCH, E. (Org.). Teorias do rádio - textos e contextos. Florianópolis: Insular, 2005. p. 199-207. v. 1.

GUATTARI, F.; ROLNIK, S. Micropolítica: Cartografias do desejo. Petrópolis: Vozes, 1999.

HAMMES, R. A conquista de espaços na comunidade. In: CONGRESSO INTERNACIONAL DE ACOMPANHAMENTO TERAPÊUTICO, 3., 2008, Porto Alegre. CONGRESSO IBERO-AMERICANO DEACOMPANHAMENTO TERAPÊUTICO, 4., 2008, Porto Alegre. CONGRESSO BRASILEIRO DE ACOMPANHAMENTO TERAPÊUTICO, 2., 2008, Porto Alegre. Anais do III Congresso Internacional, IV Congresso Ibero-Americano, II Congresso Brasileiro de Acompanhamento Terapêutico. Porto Alegre: [s.n], 2008. p. 125.

LACAN, J. O Seminário sobre "a carta roubada". In: . Escritos. Rio de Janeiro: Zahar, 1998.

LEVY, T. S. A experiência do Fora: Blanchot, Foucault e Deleuze. Rio de Janeiro: Relume Dumará, 2003.

MELLO, V. P. Papo-cabeça, a experiência de uma oficina de rádio para usuários de serviços de saúde mental. In: CONGRESSO BRASILEIRO DE CIÊNCIAS DA COMUNICAÇÃO, 24., 2001, Campo Grande. Anais do XXIV Congresso Brasileiro de Ciências da Comunicação. Campo Grande: [s.n], 2001. Disponível em: <http://reposcom.portcom.intercom.org.br/handle/1904/4961> . Acesso em: 15 jan. 2010.

MELO, A. M.; MAGNAGO, C. F. De Perto Ninguém é Normal: um processo de consolidação.In:CONGRESSOINTERNACIONALDEACOMPANHAMENTO TERAPÊUTICO, 3., 2008, Porto Alegre. CONGRESSO IBERO-AMERICANO DE ACOMPANHAMENTO TERAPÊUTICO, 4., 2008, Porto Alegre. CONGRESSO BRASILEIRO DE ACOMPANHAMENTO TERAPÊUTICO, 2. 2008, Porto Alegre. Anais do III Congresso Internacional, IV Congresso IberoAmericano, II Congresso Brasileiro de Acompanhamento Terapêutico. Porto Alegre: [s.n.], 2008. p. 122. 
OLIVERA, A. LT 22 Radio "La Colifata” Asoc. Civil Salud Mental y Comunicación. 1999. Disponível em: <http://www.projetosterapeuticos. com.br/noticia01.php?id=98>. Acesso em: 10 dez. 2009.

OLIVERA, A. Quién habla? LT 22 Radio La Colifata. 2003. Disponível em: $\quad<$ http://www.projetosterapeuticos.com.br/noticia01.php?id=98>. Acesso em: 10 dez. 2009.

PALOMBINI, A. L. Vertigens de uma psicanálise a céu aberto: a cidade. Contribuições do acompanhamento terapêutico à clínica na reforma psiquiátrica. 2007. Tese (Doutorado)-Universidade do Estado do Rio de Janeiro, Rio de Janeiro, 2007. Disponível em: <http://hdl.handle.net/10183/10191>. Acesso em 12 out. 2011.

PALOMBINI, A. L.; CABRAL, K. V.; BELLOC, M. M. Do AT à radiodifusão como estratégia de ocupação da cidade. In: CONGRESSO INTERNACIONAL DE PSICOPATILOGIA FUNDAMENTAL, 3., 2008, Niterói CONGRESSO BRASILEIRO DE PSICOPATOLOGIA FUNDAMENTAL, 9., 2008, Niterói. Anais do III Congresso Internacional e IX Congresso Brasileiro de Psicopatologia Fundamental. Niterói: [s.n.] 2008. Disponível em < http://www. fundamentalpsychopathology.org/8_cong_anais/MR_399c.pdf>. Acesso em: 15 jan. 2010.

PASSOS, E.; EIRADO, A. Cartografia como dissolução do ponto de vista do observador. In: PASSOS, E.; KASTRUP, V.; ESCÓSSIA, L. (Org.). Pistas do método da cartografia: Pesquisa-intervenção e produção de subjetividade. Porto Alegre: Sulina, 2009. p. 109-130.

PELBART, P. P. Literatura e Loucura. In: RAGO, M.; ORLANDI, L. B. L.; VEIGA-NETO, A. (Org.). Imagens de Foucault e Deleuze: ressonâncias nietzschianas. Rio de Janeiro: DP\&A, 2002. p. 287-298.

PELBART, P. P. Da Clausura do Fora ao Fora da Clausura: Loucura e Desrazão. São Paulo: Brasiliense, 1989.

PORTAL RÁDIO UNIVERSIDADE. De Perto Ninguém é Normal. Disponível em: <http://coralx.ufsm.br/radio/alfa/viewpage.php?page_id=97>. Acesso em: 15 jan. 2010.

RADIO NIKOSIA. Sobre Radio Nikosia. Disponível em: <http://radionikosia. org/about>. Acesso em: 15 janeiro 2010.

ROLDÃO, I. C. C.; MOREIRA, R. Um jornalista na loucura, despertando loucos por jornalismo. In: MERHY, E.; AMARAL, H. (Org.). A Reforma Psiquiátrica 
no Cotidiano II. São Paulo: Aderaldo \& Rothschild, 2007, p. 67-81.

SERVIÇO DE SAÚDE DR. CÂNDIDO FERREIRA. Serviço de Saúde Dr. Cândido Ferreira. Disponível em: <http://www.candido.org.br/>. Acesso em: 15 jan. 2010.

SCHÉRER, R. Homo tantum. O impessoal: uma política. In: ALLIEZ, É. (Org.). Gilles Deleuze: uma vida filosófica. São Paulo: 34, 2000. p. 21-38.

SCHÓPKE, R. Por uma filosofia da diferença: Gilles Deleuze, o pensador nômade. São Paulo: Edusp, 2004.

SILVA, L. B. C. Três questões sobre as psicoses: uma leitura de O Anti-Édipo. Mental, Barbacena, v. 2, n. 4, p. 113-131, jun. 2005.

STREPPEL, F. F.; GORCZEVSKI, D.; PALOMBINI, A. L. Rádio-acontecimento: modos de comunicar Potência Mental. Revista Periferia, Rio de Janeiro, v. 2, n. 1, p. 1-16, jan./jun. 2010.

STREPPEL, F. F.; PALOMBINI, A. L. Potência Mental no ar... Exercícios de esquizo-radiofonia. 2011. Dissertação (Mestrado)-Universidade Federal do Rio Grande do Sul, Porto Alegre, 2011.

TIBULO, A. P. et al. Programa de Rádio Potência Mental busca seu espaço. In: CONGRESSO INTERNACIONAL DE SALUD MENTAL E DERECHOS HUMANOS, 5., 2006, Buenos Aires. Anais do V Congresso Internacional de Salud Mental e Derechos Humanos. Buenos Aires: [s.n], 2006.

Recebido em: 21 de maio de 2010 Aceito em: 20 de outubro de 2011 